\title{
Article \\ Phenolics and Mineral Elements Composition in Underutilized Apple Varieties
}

\author{
Alessandra Francini ${ }^{*}+{ }^{+} \mathbb{C}$, Carmen Fidalgo-Illesca ${ }^{\dagger}$, Andrea Raffaelli $\mathbb{C}$ and Luca Sebastiani $\mathbb{\oplus}$ \\ BioLabs, Institute of Life Sciences, Scuola Superiore Sant'Anna, Piazza Martiri della Libertà 33, 56127 Pisa, Italy; \\ c.fidalgoillesca@santannapisa.it (C.F.-I.); andrea1.raffaelli@santannapisa.it (A.R.); \\ luca.sebastiani@santannapisa.it (L.S.) \\ * Correspondence: a.francini@santannapisa.it; Tel.: +39-050-883-151 \\ + These authors contributed equally to this work.
}

check for updates

Citation: Francini, A.; Fidalgo-Illesca,

C.; Raffaelli, A.; Sebastiani, L. Phenolics and Mineral Elements Composition in Underutilized Apple Varieties. Horticulturae 2022, 8, 40. https: / / doi.org/10.3390/

horticulturae 8010040

Academic Editors: Jelena Popović-Djordjević and Luiz Fernando Cappa de Oliveira

Received: 6 December 2021

Accepted: 28 December 2021

Published: 30 December 2021

Publisher's Note: MDPI stays neutral with regard to jurisdictional claims in published maps and institutional affiliations.

Copyright: (C) 2021 by the authors. Licensee MDPI, Basel, Switzerland. This article is an open access article distributed under the terms and conditions of the Creative Commons Attribution (CC BY) license (https:// creativecommons.org/licenses/by/ $4.0 /)$.

\begin{abstract}
Background: The aim of this research is to study the importance of improving knowledge of old variety apples in terms of phytochemicals, antioxidant capacity and mineral elements. (2) Methods: Fifteen phenolic compounds (UHPLC-MS/MS techniques), eight mineral elements (Ca, K, $\mathrm{Cu}, \mathrm{Mn}, \mathrm{Fe}, \mathrm{Zn}, \mathrm{Na}$ and $\mathrm{Mg}$ ), antioxidant capacity (DPPH\%) and vitamin $\mathrm{C}$ content in four ancient apple varieties of Tuscany ('Mora', 'Nesta', 'Panaia' and 'Ruggina'), with the 'Golden Delicious' cultivar as reference, were analyzed. (3) Results: Ancient cultivars exhibited a superior antioxidant capacity compared to commercial cultivars. ECTC and CGA were the polyphenols that mostly characterized the ancient apples. The contents of the elements of concern, $\mathrm{Zn}$ and Mn, were higher in the ancient cultivars 'Panaia' and 'Ruggina', while Na showed significant low concentration in 'Nesta', 'Panaia' and 'Ruggina' compared to 'Golden Delicious'. The vitamin C content also indicated that 'Mora', 'Panaia' and 'Ruggina' old variety had an AsA content around 10 times higher than the 'Golden Delicious' apple. (4) Conclusions: Underutilized varieties could be an excellent source of bioactive phenolic phytochemicals, mineral nutrients and vitamins that may offer special nutraceutical benefits compared to other fruits.
\end{abstract}

Keywords: polyphenols; vitamin C; old cultivars; ·antioxidant capacity

\section{Introduction}

Among secondary metabolites, polyphenols are considered interesting for human nutrition due to their capacity to modulate several cell-signaling pathways and for their positive effects in a wide range of human pathologies [1]. Similarly, a regular intake of mineral elements, such as $\mathrm{Ca}, \mathrm{Mn}$ and $\mathrm{K}$ is essential in controlling the permeability of the cell membrane, release of hormones and intermediaries of the nervous system [2].

Fruits, and in particular apples, have been recognized as a source of health-promoting bioactive compounds [3-5] as well as of several mineral elements essential for human nutrition [6].

The phenolics and mineral element composition in fruits and vegetables depend on pedoclimatic conditions, agronomic practices, and genotype [7]. Moreover, processing techniques and postharvest storage largely affect their concentrations in the final products $[4,8,9]$.

In the last decades, breeding approaches have selected genetic material that possess consumer attractive merceological traits, such as regular shape and larger size, as well as sweetness. Unfortunately, these fruit traits are often inversely correlated with a high polyphenol concentration [10]. Despite their less attractive pomological properties, several underutilized apple cultivars (Malus domestica Borkh.) have shown higher concentrations of polyphenols, flavanols, phenolic acids and flavanols [10,11], and high antioxidant capacity when compared to the commercially well-established and actually cultivated varieties [12-16]. Other relevant characteristics linked to the hypoallergenic properties of some of these underutilized cultivars could be used in apple-based products [17]. 
Since underutilized varieties are recognized as a potential source of health-promoting bioactive compounds $[3,5,11]$, there is a growing interest in the fine characterization of these genetic material. By reviewing the literature, it is evident that research activity has mainly focused on the phenolic composition and antioxidant properties of apples while the analysis of these traits in conjunction with mineral composition is missing.

The aim of this study is to provide a comprehensive characterization of a set of underutilized apple cultivars in comparison to a commercial and well-diffused variety grown in the same cultivation area. Using liquid chromatography-electrospray ionization mass spectrometry (LC-ESI-MS/MS) and microwave plasma-atomic emission spectrometry (MP-AES), we identify which phenolics and mineral elements characterize the different cultivars. Moreover, spectrophotometric assay was carried out to determine the antioxidant capacity and vitamin $C$ in apples. These data could be useful for improving the biological values of apple genetic material.

\section{Materials and Methods}

\subsection{Chemicals}

p-coumaric acid (PCA), trans-ferulic acid (TFRA) phloretin (PHL), (+)-catechin (CTC), (-)-epicatechin (ECTC), quercetin (QCT), chlorogenic acid (CGA) Phloridzin (PDZ), kaempferol 3-O-glucoside (KPF3G), kaempferol 7-O-glucoside (KPF7G), quercetin 3-Oglucoside (QCT3G), quercetagetin 7-O-glucoside (QGT7G), tiliroside (TSD), kaempferol 3-O-rutinoside (KPF3R); rutin (RTN), HPLC grade methanol, acetonitrile, $\mathrm{Na}_{2} \mathrm{CO}_{3}$, formic acid, 1,1-diphenyl-2-picrylhydrazyl, L-ascorbic acid and bathophenanthroline were purchased from Sigma-Aldrich (Milan, Italy). Ultra-pure water purified by Milli-Q System (Millipore, Milan, Italy) was used to prepare aqueous solution.

\subsection{Apple Fruits}

Five apple (Malus $\times$ domestica Borkh.) varieties were used: (a) 'Mora', 'Nesta', 'Ruggina', 'Panaia' genotypes belonging to the underutilized apple cultivars germplasm; and (b) 'Golden Delicious'. This cultivar was chosen as a reference due to its importance in the global and Italian varietal assortment. All plants were grafted on the M9 rootstock and cultivated in the Casentino area (Tuscany, Italy) according to standard guidelines for integrated apple production. Three independent samples of 5 apples (each fruit collected from a different plant) were analyzed for each cultivar. The flesh firmness $\left(\mathrm{N} / \mathrm{cm}^{2}\right)$ was measured with a fruit penetrometer removing the apple peel and measuring in 2 different points of apple fruits harvested at commercial maturity. Data were $30 \pm 4.8,32 \pm 8.5,30 \pm$ 3.6, $21 \pm 4.0$ and $53 \pm 13.4$ for 'Golden Delicious', 'Mora', 'Nesta', 'Panaia' and 'Ruggina', respectively. The soluble solids content was determined using a hand-refractometer at 20 ${ }^{\circ} \mathrm{C}$ and ${ }^{\circ}$ Brix measured were $15 \pm 1.5,15 \pm 1.6,13 \pm 0.8,15 \pm 1.4$, and $18 \pm 2.0$ for 'Golden Delicious', 'Mora', 'Nesta', 'Panaia' and 'Ruggina', respectively.

\subsection{Sampling Procedure, Polyphenols Extraction and LC-MS Analysis}

After being washed, all 5 apples composing each sample $(n=3)$ were divided into four sections along the vertical axis, the core and seeds were removed, and all the sections pooled together. A representative portion was then quickly frozen in liquid nitrogen and stored in $-80{ }^{\circ} \mathrm{C}$ for subsequent analyses. Polyphenol compounds were extracted from a representative portion of $7.5 \mathrm{~g}$ using $25 \mathrm{~mL}$ of $80 \%$ HPLC-grade methanol (SigmaAldrich, Milan, Italy). Extraction was carried out at room temperature $\left(25^{\circ} \mathrm{C}\right)$ and samples were shaken (laboratory shaker VDRL mod. 711/CS ASAL, Milano, Italy) for $30 \mathrm{~min}$. The extracts were filtered through a membrane of $0.45 \mu \mathrm{m}$ pore size prior to injection in LC-ESI-MS/MS to identify and quantify the selected phenolic compounds.

Targeted quantitative analyses of selected known polyphenols were performed in the extracts by LC-MS/MS using a Sciex 5500 QTrap+ mass spectrometer (AB Sciex LLC, Framingham, MA, USA), equipped with a Turbo V ion-spray source and coupled to an 
ExionLC AC System by Shimadzu (Shimadzu Corporation, Kyoto, Japan), which consist of ExionLC Controller, Degasser, Tray, Autosampler and 2 ExionLC AC Pumps.

Chromatographic separation was performed by a Phenomenex Kinetex EVO $2 \times 100 \mathrm{~mm}$, $5 \mu \mathrm{m}$ column (Phenomenex, Torrance, CA, USA). An elution gradient was carried out with acetonitrile containing $0.1 \%$ formic acid (solvent $\mathrm{A}$ ) and water with $0.1 \%$ formic acid (solvent B). The gradient elution consisted of $0.0 \mathrm{~min}$, A 5\%; 0.0-10.0 min, A 5-95\%; 10.0-12.0 min, A 95\%; followed by 4 min equilibration time (A 5\%). The column oven temperature was set up at $40{ }^{\circ} \mathrm{C}$, the flow rate $300 \mu \mathrm{L} \mathrm{min}{ }^{-1}$ and the injection volume was $20 \mu \mathrm{L}$.

MS/MS experiments were performed in electrospray negative ion mode using nitrogen as collision gas and the following operation source parameters: source type, turbo spray; nebulizer gas (GS1) 70 (arbitrary units); turbo gas (GS2) 50 (arbitrary units); curtain gas (CUR) 10 (arbitrary units); temperature (TEM) $500{ }^{\circ} \mathrm{C}$; ion spray voltage (IS) $-4500 \mathrm{~V}$, entrance potential (EP) $10 \mathrm{~V}$. Compound parameters, declustering potential (DP), collision energy (CE), collision cell exit potential (CXP) were adjusted for the specific selected reaction monitoring (SRM) transition for any component (Table 1).

Table 1. Selected reaction monitoring transitions and optimized method and retention times (RT) of selected phenolic compounds.

\begin{tabular}{lccccccc}
\hline Name & Acronym & RT (min) & Q1 & Q3 & DP (V) & CE (eV) & CXP (V) \\
\hline Catechin & CTC & 2.33 & 289.0 & 244.9 & -108 & -22 & -11 \\
Chlorogenic Acid & CGA & 2.44 & 353.0 & 191.0 & -61 & -24 & -9 \\
Epicatechin & ECTC & 2.63 & 289.0 & 244.9 & -108 & -22 & -11 \\
Quercetagetin & Q7G & 3.07 & 479.1 & 316.9 & -152 & -31 & -14 \\
7-O-Glucoside & PCA & 3.09 & 163.0 & 119.0 & -65 & -18 & -11 \\
p-Coumaric Acid & TFRA & 3.28 & 193.0 & 134.0 & -62 & -20 & -8 \\
trans-Ferulic Acid & RTN & 3.30 & 609.2 & 299.9 & -154 & -48 & -11 \\
Rutin & QCT3G & 3.40 & 463.1 & 300.0 & -154 & -37 & -5 \\
Quercetin & & & & & & & \\
3-O-Glucoside & KPF3R & 3.53 & 593.2 & 284.9 & -138 & -40 & -5 \\
Kaempferol & & & & & & & \\
3-O-Rutinoside & KPF3G & 3.62 & 447.1 & 284.1 & -202 & -39 & -11 \\
Kaempferol & & & & & & & \\
3-O-Glucoside & KPF7G & 3.66 & 447.1 & 284.9 & -158 & -38 & -5 \\
Kaempferol & PDZ & 3.71 & 435.1 & 272.9 & -135 & -23 & -5 \\
7-O-Glucoside & QCT & 4.30 & 301.0 & 150.9 & -113 & -38 & -8 \\
$\begin{array}{l}\text { Phloridzin } \\
\text { Quercetin }\end{array}$ & TSD & 4.41 & 593.2 & 284.9 & -138 & -40 & -5 \\
$\begin{array}{l}\text { Tiliroside } \\
\text { Phloretin }\end{array}$ & PHL & 4.64 & 273.0 & 167.0 & -103 & -38 & -11 \\
\hline
\end{tabular}

The matrix effect and recovery percentage were used to normalize the data. Matrix effect was calculated as peak area of the sample spiked after extraction/peak area of the standard, while recovery was calculated as peak area of the sample spiked before extraction/peak area of the sample spiked after extraction. The analytical parameters were optimized by infusing a standard solution of each polyphenol $\left(1 \mathrm{mg} \mathrm{L}^{-1}\right.$ in methanol/water $(1: 1, \mathrm{~mL}: \mathrm{mL}))$ into the source at a flow rate of $0.01 \mathrm{~mL} \mathrm{~min}^{-1}$.

\subsection{Vitamin C Content and DPPH Assay}

Vitamin $C$ concentration was determined in the methanol extract of fresh apples following the method of Francini et al. [18]. Briefly, the analysis consists of the reduction of ferric to ferrous ion by ascorbic acid in acidic solution that produce a red chelate between ferrous ion and 4,7-diphenyl-1,10-phenanthrolin (bathophenanthroline), which absorbs at $534 \mathrm{~nm}$. The AsA standard curve, in the range $0-10 \mathrm{nmol}$, was used as reference.

An amount of $200 \mu \mathrm{L}$ of methanol extract apples was used to assay the scavenging activity of 1,1-diphenyl-2-picrylhydrazyl (DPPH) radicals after mix with $800 \mu \mathrm{L}$ of Tris-HCl $100 \mathrm{mM}$ solution $\mathrm{pH}$ 7.0. One $\mathrm{mL}$ of methanol solution of DPPH $250 \mu \mathrm{M}$ was added to this mix and maintained for $30 \mathrm{~min}$ in the dark; absorbance was measured at $517 \mathrm{~nm}$ and methanol was used as reference. The percentage of DPPH scavenging was calculated 
as: scavenging ratio $(\%)=[$ (absorbance of control - absorbance of sample) (absorbance of control)].

\subsection{Cation Concentration}

Mineral element ( $\mathrm{Mg}, \mathrm{Ca}, \mathrm{K}, \mathrm{Zn}, \mathrm{Cu}, \mathrm{Mn}, \mathrm{Fe}$ and $\mathrm{Na}$ ) concentrations were determined on apple dry samples. Briefly, approximately $0.3 \mathrm{~g}$ of dry apples (peel and pulp) were added to $8.0 \mathrm{~mL}$ of $65 \%$ nitric acid. The mixture was digested using the COOLPEX Smart Microwave Reaction System (Yiyao Instrument Technology Development Co., Ltd., Shanghai, China). The digested solution was diluted with Milli-Q $\mathrm{H}_{2} \mathrm{O}$, and then analyzed. The mineral elements quantification was performed with a Microwave Plasma-Atomic Emission Spectrometer (4210 MP-AES, Agilent Technologies, Santa Clara, CA, USA). Daucus carota (L.) leaf tissue was used as analytical standard reference (WEPAL IPE, Wageningen University, Wageningen, The Netherlands). A multi-element standard control was prepared in $5 \% \mathrm{HNO}_{3}(v / v)$ medium and diluted with Milli-Q $\mathrm{H}_{2} \mathrm{O}$ for mineral determinations.

\subsection{Statistical Analyses}

All data are presented as mean \pm SD of three independent replicates, each prepared using 5 apples from different plants. Graph Pad prism 6.0 (GraphPad software, San Diego, CA, USA) was used for one-way analysis of variance (one-way ANOVA) and Tukey's post-hoc. The differences were considered significant with $p<0.05$. Principal component analysis (PCA) was applied using NCSS 2004 Statistical Analysis System Software, to highlight a natural grouping of samples depending on the variables measured in relation to the different apples studied. For these PCA the Varimax rotation was applied on the obtained factor.

\section{Results}

A panel of 15 polyphenols, 2 flavanols (catechin and epicatechin), 7 flavanols (quercetagetin 7-O-glucoside, rutin, quercetin 3-O-glucoside, kaempferol 3-O-rutinoside, kaempferol 7-O-glucoside, kaempferol 3-O-glucoside and quercetin), 1 cinnamate ester (chlorogenic acid), 2 hydroxy-cinnamic acids ( $p$-coumaric and trans-Ferulic acid), 2 dihydrochalcones (phloridzin and phloretine) and 1 oxyflavone (tiliroside) was taken into consideration, based on previous investigations. A single SRM transition was selected for the LC-MS/MS analysis and used for analytes quantitation. Qualitative confirmation was acquainted with taking advantage of one of the features of a QTrap instrument. Information dependent acquisition (IDA) was programmed so that the SRM transitions reported in Table 1 were used as a survey scan, switching the third quadrupole to act as a linear ion trap (LIT), performing an enhanced product ions (EPI) scan, affording the complete MS-MS product ions spectrum (MRM $>>$ enhanced product experiment). The qualitative data confirmation was performed using a custom-built MS-MS product ions spectra library.

Among the polyphenols analyzed (Figure 1), ECTC is the most abundant, reaching a value of $330 \pm 35.0 \mu \mathrm{g} \mathrm{g}^{-1} \mathrm{FW}$ in 'Ruggina', 3.9 time higher than 'Golden Delicious' (Figure 1A). CGA is the second abundant compound with a concentration significant different between 'Golden Delicious', 'Nesta' and 'Panaia' (54, 123 and $153 \mu \mathrm{g} \mathrm{g}^{-1} \mathrm{FW}$, respectively) (Figure 1B). PDZ and RTN are significantly higher in 'Panaia' (27.7 $\pm 1.88 \mu \mathrm{g} \mathrm{g}^{-1} \mathrm{FW}$ and $2.2 \pm 0.05 \mu \mathrm{g} \mathrm{g}{ }^{-1} \mathrm{FW}$, respectively) when compared to the other cultivars analyzed (Figure 1E,G). Regarding other phenolic compounds, KPF3R and TFRA are poorly represented in all apple cultivars (Figure $1 \mathrm{~N}, \mathrm{O}$ ). 

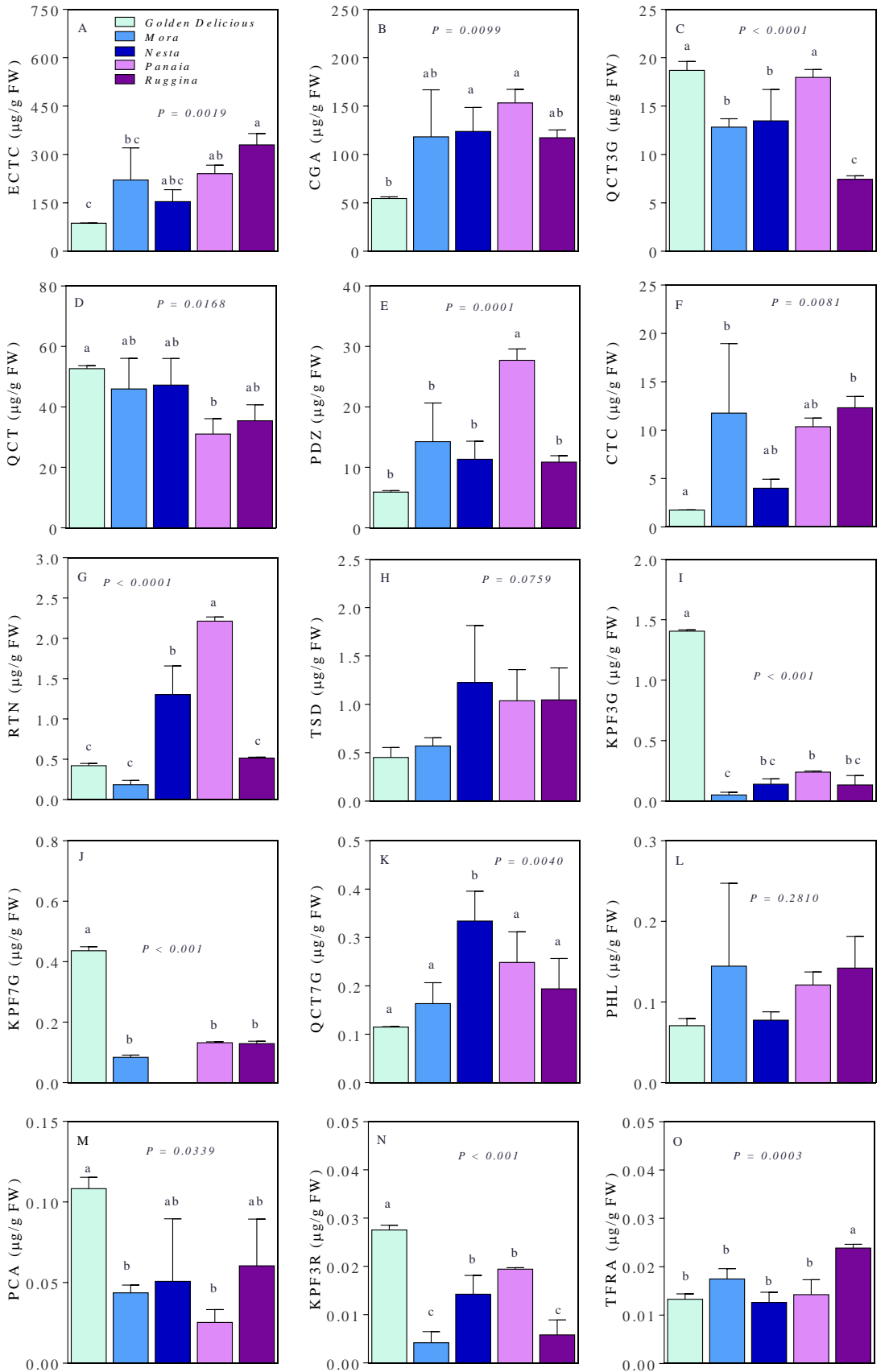

Figure 1. Mean values and standard deviations for concentrations ( $\mu \mathrm{g} g-1 \mathrm{FW}$ ) of (A) (-)-epicatechin (ECTC), (B) chlorogenic acid (CGA), (C) quercetin 3-O-glucoside (QCT3G), (D) quercetin (QCT), (E) phloridzin (PDZ), (F) (+)-catechin (CTC), (G) rutin (RTN), (H) tiliroside (TSD), (I) kaempferol 3-O-glucoside (KPF3G), (J) kaempferol 7-O-glucoside (KPF7G), (K) quercetagetin 7-O-glucoside (QGT7G), (L) phloretin (PHL), (M) p-coumaric acid (PCA), (N) kaempferol 3-O-rutinoside (KPF3R), (O) trans-ferulic acid (TFRA) determined by the analysis of QTRAP for fresh apples. Data $(n=3)$ were analyzed by one-way ANOVA. Tukey's post-hoc test at 0.05 probability level was applied and different letters indicated significant difference among means.

Considering the sum of all the 15 phenolic compounds analyzed (Figure 2), it was evident that cultivars such as 'Panaia' and 'Ruggina' have the higher concentration of polyphenols in comparison to 'Golden Delicious'. The sum of the 15 polyphenols ranged between $222 \pm 5 \mu \mathrm{g} \mathrm{g}^{-1} \mathrm{FW}$ in 'Golden Delicious' < $356 \pm 77 \mu \mathrm{g} \mathrm{g}^{-1} \mathrm{FW}$ in 'Nesta' < $426 \pm 166 \mu \mathrm{g} \mathrm{g}^{-1} \mathrm{FW}$ in 'Mora' $<485 \pm 49 \mu \mathrm{g} \mathrm{g}^{-1} \mathrm{FW}$ in 'Panaia' $<515 \pm 49 \mu \mathrm{g} \mathrm{g}^{-1} \mathrm{FW}$ in 'Ruggina'. 


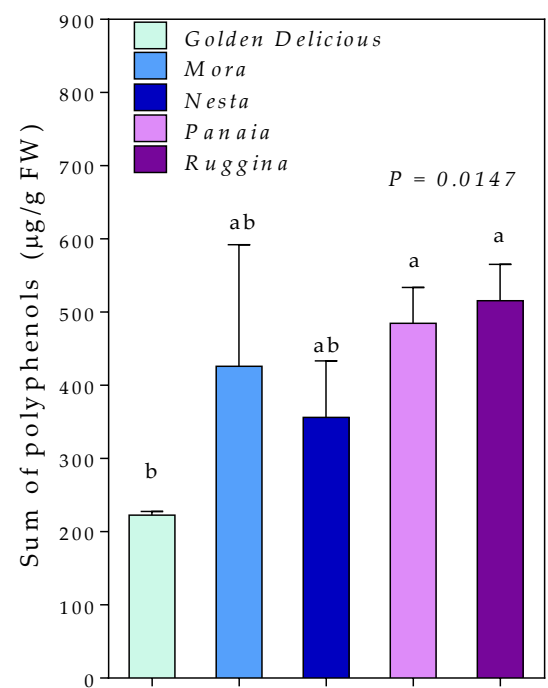

Figure 2. Total phenolic concentration calculated as sum of a panel of 15 polyphenols measured. Data $(n=3)$ were analyzed by one-way ANOVA. Tukey's post-hoc test at 0.05 probability level was applied and different letters indicated significant difference among means.

The DPPH radical scavenging test provided a broad picture of the antioxidant properties of the apple cultivars studied and results are presented in Table 2. Data showed high variability of DPPH radical scavenging capacity among cultivars and the decreasing order was 'Mora' > 'Ruggina' $\geq$ 'Panaia' $\geq$ 'Golden Delicious' $>$ 'Nesta'. The highest antioxidant activity was measured in 'Mora' (55.1 $\pm 5.23 \%)$ while the lowest was observed in 'Nesta' $(3.3 \pm 2.63 \%)$; 'Ruggina' also showed a strong activity ( $41 \%$ after 5 min of incubation). As concern the amount of vitamin C (mg $\left.100 \mathrm{~g}^{-1} \mathrm{FW}\right)$ data indicated that 'Golden Delicious' AsA content was around 10 times lower than those measured for 'Mora', 'Panaia' and 'Ruggina' and three times lower than 'Nesta' (Table 2).

Table 2. The inhibition of 1-diphenyl-2-picrylhydrazyl radical activity (DPPH \%) and vitamin C (mg $\left.100 \mathrm{~g}^{-1} \mathrm{FW}\right)$ content in fresh apples.

\begin{tabular}{lcc}
\hline Name & DPPH (\%) & Vitamin C $\left.\mathbf{( m g ~} \mathbf{1 0 0} \mathbf{~ g}^{-\mathbf{1}} \mathbf{F W}\right)$ \\
\hline Golden Delicious & $23.7 \pm 3.43 \mathrm{c}$ & $0.39 \pm 0.140 \mathrm{c}$ \\
Mora & $55.1 \pm 5.23 \mathrm{a}$ & $3.43 \pm 0.054 \mathrm{a}$ \\
Nesta & $3.30 \pm 2.63 \mathrm{~d}$ & $1.27 \pm 0.056 \mathrm{~b}$ \\
Panaia & $33.3 \pm 5.48 \mathrm{bc}$ & $3.06 \pm 0.125 \mathrm{a}$ \\
Ruggina & $41.1 \pm 3.93 \mathrm{~b}$ & $3.30 \pm 0.343 \mathrm{a}$
\end{tabular}

Data $(n=3)$ were analyzed by one-way ANOVA. Tukey's post-hoc test at 0.05 probability level was applied and different letters indicated significant difference among means.

The concentration of the eight mineral elements, evaluated in underutilized and 'Golden Delicious' cultivars, are displayed in Figure 3. Data show that $\mathrm{Na}, \mathrm{Mg}, \mathrm{Ca}$ and $\mathrm{K}$ were the most abundant elements and concentrations varied significantly among the cultivars (Figure 3D,F-H). 'Ruggina' had the highest Zn concentration (Figure 3A) and with 'Panaia' the highest amount of Mn and Mg (Figure 3B,F). 'Nesta' showed the highest Ca concentration while 'Panaia' the lowest (Figure 3G). Compared to 'Golden Delicious', 'Mora' presented a lower value of $\mathrm{Cu}$ (Figure 3C).

Bidimensional plots of sample loadings and scores in the space (first two principal components) are shown in Figure 4. The PCA of five apple cultivars indicated that the first two principal components (PC1 and PC2) accounted for $50.6 \%$ of the total variability. The variables that contributed more to the PC1 (28.7\%) were TFRA, PHL, CTC, ECTC, QCT, QCT3G, TSD and KPF3R; than the mineral elements $\mathrm{Fe}, \mathrm{Ca}, \mathrm{Mn}$ and $\mathrm{Cu}$ and finally AsA. The PC2 (21.9\%) was related with PCA, CGA, PDZ, KPF3G, QGT7G, Na, Mg, K and Zn. All cultivars result separated to each other and in particular 'Panaia', 'Ruggina' and 
'Mora', resulting in the part with the higher concentrations of the antioxidant molecules and mineral elements. Among the four underutilized cultivars, it appears evident that a larger variability exists as indicated by their spatial spread in the graph.
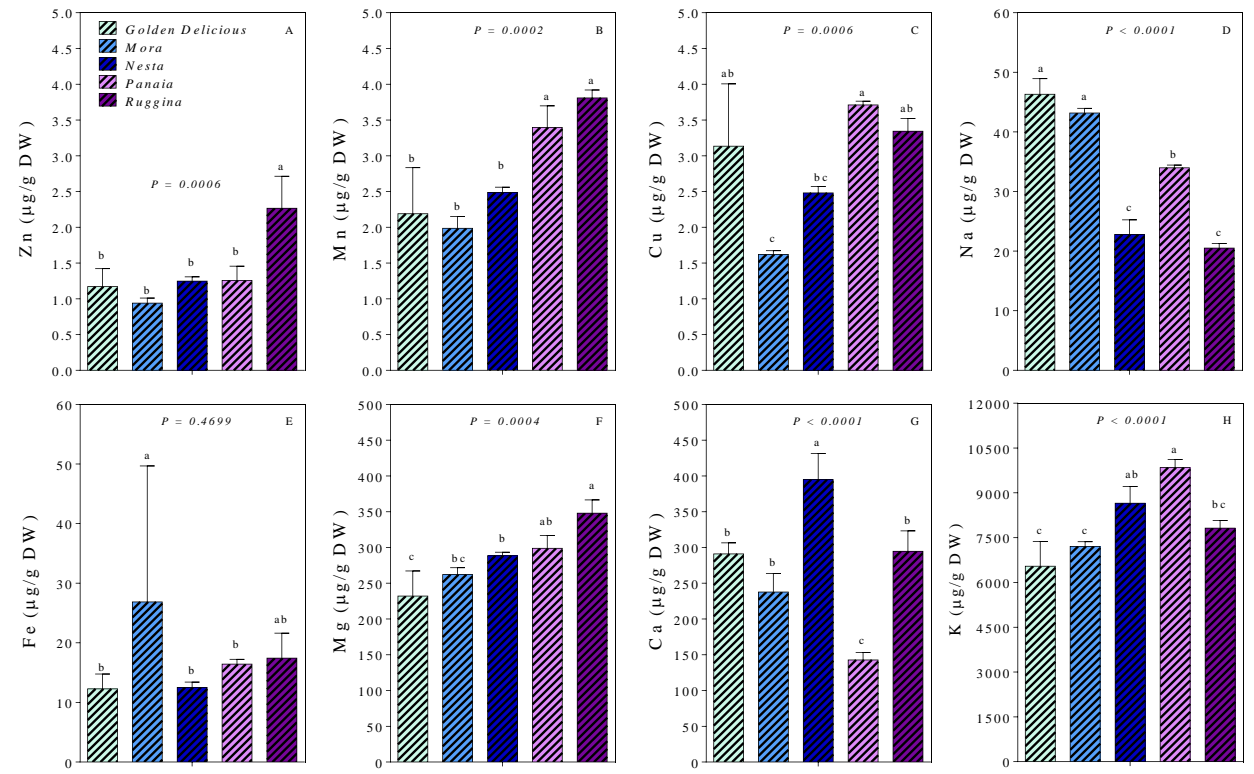

Figure 3. Concentrations of (A) $\mathrm{Zn},(\mathbf{B}) \mathrm{Mn},(\mathbf{C}) \mathrm{Cu}$, (D) $\mathrm{Na}$, (E) Fe, (F) $\mathrm{Mg}$, (G) Ca and (H) $\mathrm{K}\left(\mu \mathrm{gg}^{-1}\right.$ of dry weight), in the different apple cultivars. Data $(n=3)$ were analyzed by one-way ANOVA. Tukey's post-hoc test at 0.05 probability level was applied and different letters indicated significant difference among means.

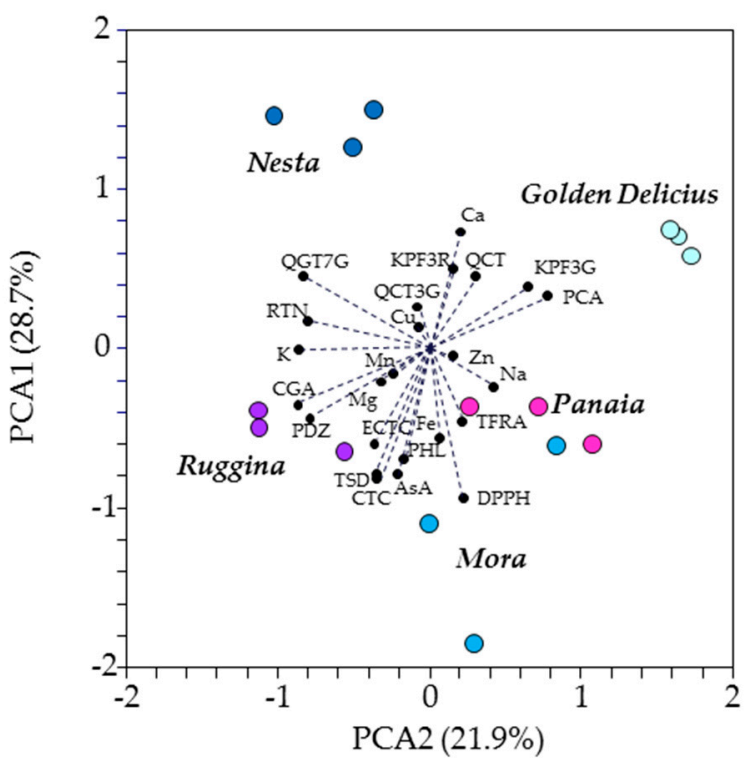

Figure 4. Principal component analysis of polyphenols profile ((-)-epicatechin (ECTC), chlorogenic acid (CGA), quercetin 3-O-glucoside (QCT3G), quercetin (QCT), phloridzin (PDZ), (+)-catechin (CTC), rutin (RTN), tiliroside (TSD), kaempferol 3-O-glucoside (KPF3G), kaempferol 7-O-glucoside (KPF7G), quercetagetin 7-O-glucoside (QGT7G), phloretin (PHL), p-coumaric acid (PCA), trans-ferulic Acid (TFRA), kaempferol 3-O-rutinoside (KPF3R), antioxidant capacity (DPPH) and mineral element composition ( $\mathrm{Zn}, \mathrm{Mn}, \mathrm{Cu}, \mathrm{Na}, \mathrm{Fe}, \mathrm{Mg}, \mathrm{Ca}$ and $\mathrm{K}$ ) of four ancient apple cultivars from Tuscany ('Mora', 'Nesta', 'Panaia' and 'Ruggina') and the commercial variety 'Golden Delicious'.

\section{Discussion}

The diet is the principal source of polyphenolic compounds and fruits rich in polyphenols are interesting for improving human health. The bioavailability of polyphenols 
depends on a variability of aspects, such as the release from the food matrix during gastrointestinal digestion, the cellular uptake, metabolism, and the transport in the circulatory system [19]. An example is given by chlorogenic acid, a molecule representing a major polyphenol in apples, that undergoes drastic reduction in bioavailability following digestion [19]. Consumers interested in the beneficial health effects of fruit should pay attention to the concentration variability that characterizes the cultivars.

In this study, data about polyphenol concentrations in 'Panaia' and 'Ruggina' confirm a previous study carried out by Iacopini et al. [13]. In particular, these two varieties showed a high level of ECTC (the most abundant polyphenol) in comparison to 'Golden Delicious'. Among the different polyphenols, Preti and Tarola [15] showed that catechins and epicatechin are the most abundant also in 'Ruggine Dorata' and 'Di Corone', underutilised cultivars grown in Friuli Venezia Giulia (Northeast Italy). Data reported by Petri and Tarola [15] are in the range of our data. These two molecules have been proposed as an effective chemical defense of apple fruit against rust infection [20] as also previously shown in rust-infected symptomatic leaves of Malus [21]. The concentrations of phloretin and phloridzin identified by the HPLC-DAD-MS/MS analysis by Zielinska et al. [22] in the peel and flesh of 11 high-quality grade apple cultivars from Poland, showed comparable values to our varieties. The phloretin and its glycoside phloridzin, which is found exclusively in apples, improve insulin sensitivity and enhance glucose uptake [23]. Moreover, phloridzin is also used as a marker of undeclared addition of apples in other fruit products [24]. The phenolic profile of our underutilized varieties is very remarkable and merits further investigation since the total level of all polyphenols appeared to be higher than that found in 'Golden Delicious'.

Apples are also an important source of vitamins and minerals with a high nutritional value. Consumers need food sources that are rich in $\mathrm{K}, \mathrm{Ca}, \mathrm{Mg}, \mathrm{Zn}$, and poor in $\mathrm{Na}$. In apples, $\mathrm{K}$ constitutes the main portion of the mineral element, and the $\mathrm{Ca}$ is the second. Of concern the concentration of Ca has been associated with post-harvest disorders, such as senescent breakdown [25]. For a commercial point of view, it is desirable for storage that apple fruits contain more Ca. Among the underutilized varieties, 'Nesta' showed a higher level of Ca compared to 'Golden Delicious'. Our data of macro elements (Ca, $\mathrm{K}$ and $\mathrm{Mg})$ and micro elements $(\mathrm{Cu}, \mathrm{Fe}, \mathrm{Mn}$, and $\mathrm{Zn})$ concentrations agree with those obtained by Macit et al. [26] on apple varieties in Anatolia. K was the most abundant with an overall mean concentration of $8013 \mu \mathrm{g} \mathrm{g}^{-1} \mathrm{FW}$. This result is in the range with the data reported for apple fruits by Horsley et al. [27]—10,226 mg kg${ }^{-1}$, and Ozcan et al. [28] -7000 mg kg ${ }^{-1}$. Compared to 'Golden Delicious', 'Nesta' and 'Panaia' may be a good source of $\mathrm{K}$, an element that plays an important role in human nutrition, as reported in the review of Udensi and Tchounwou [29], highlighting the major factors involved in $\mathrm{K}$ homeostasis (dietary, hormonal, genetic, and physiologic influences), and the major diseases and abnormalities associated with potassium imbalance. As reported by Todea et al. [30] and confirmed by our data, the highest values of Na were observed in 'Golden Delicious'. Considering that the World Health Organization recommends not more than 2 milligrams (mg) a day [31], 'Nesta', 'Panaia' and 'Ruggina' could in this respect be a better choice than 'Golden Delicious'.

The AsA content of 64 apple cultivars was analyzed by Bassi et al. [32] along with the sample set including 16 underutilized varieties. Data indicated that 'Golden Delicious', had an AsA content of less than $1.5 \mathrm{mg} 100 \mathrm{~g}^{-1} \mathrm{FW}$ in the pulp, 10 times lower than the analyzed underutilized varieties. These results are in line with our data confirming a general trend that the underutilized varieties have a higher AsA concentration when compared to 'Golden Delicious'.

\section{Conclusions}

Data confirm the importance of knowing the nutritional composition of apple varieties. Underutilized varieties could be an excellent source of bioactive phenolic phytochemicals, 
mineral nutrients and vitamins that may provide special nutraceutical benefits compared to other fruits. Different aspects could be highlighted:

(1) Promote quality products with higher nutritional properties (polyphenols, vitamin C and mineral nutrients);

(2) Develop cultivars with recognized dietetic qualities and encourage fruit growers to re-introduce selected and underutilized germplasms;

(3) Encourage plant breeders in investigating underutilized varieties as sources of traits for resistance to diseases or harsh environmental conditions.

Author Contributions: L.S. and A.F. conceived the idea, compiled the information, and drafted the manuscript; C.F.-I. and A.F. performed polyphenols extractions, DPPH, Vitamin C and mineral elements analyses; A.R. developed the LC-MS/MS quantitation method with qualitative confirmation by IDA scan; A.R., L.S. and A.F. performed UHPLC-ESI-MS/MS analyses; L.S., A.F. performed the statistical analysis. A.F. and L.S. reviewed and edited the manuscript. All authors have read and agreed to the published version of the manuscript.

Funding: PiAnta project granted (CUP J54I19000770002) by Regione Toscana, POR FESR 20142020 for part of the equipment used (4210 MP-AES and Sciex 5500 QTrap+, 4210 MP-AES, Agilent Technologies).

Data Availability Statement: The data that support the findings of this study are available from the corresponding author upon reasonable request.

Acknowledgments: The authors are grateful to Luca Segantini for the assistance in apple sampling in the Casentino Area.

Conflicts of Interest: The authors declare no conflict of interest.

\section{References}

1. Silva, R.F.M.; Pogačnik, L. Polyphenols from Food and Natural Products: Neuroprotection and Safety. Antioxidants 2020, 9, 61. [CrossRef]

2. Soetan, K.O.; Olaiya, C.O.; Oyewole, E. The importance of mineral elements for humans, domestic animals and plants: A review. Afr. J. Food Sci. 2010, 4, 200-222.

3. Felice, F.; Maragò, E.; Sebastiani, L.; Di Stefano, R. Apple juices from ancient Italian cultivars: A study on mature endothelial cells model. Fruits 2015, 70, 361-369. [CrossRef]

4. Francini, A.; Sebastiani, L. Phenolic Compounds in Apple (Malus $\times$ domestica Borkh.): Compounds characterization and stability during postharvest and after processing. Antioxidants 2013, 2, 181-193. [CrossRef] [PubMed]

5. Cantini, C.; Salusti, P.; Romi, M.; Francini, A.; Sebastiani, L. Sensory profiling and consumer acceptability of new dark cocoa bars containing Tuscan autochthonous food products. J. Food Sci. Nutr. 2018, 6, 245-252. [CrossRef] [PubMed]

6. Melse-Boonstra, A. Bioavailability of Micronutrients From Nutrient-Dense Whole Foods: Zooming in on Dairy, Vegetables, and Fruits. Front. Nutr. 2020, 7, 101. [CrossRef]

7. Heimler, D.; Romani, A.; Ieri, F. Plant polyphenol content. Soil fertilization and agricultural management: A review. Eur. Food Res. Technol. 2017, 243, 1107-1115. [CrossRef]

8. Starowicz, M.; Achrem-Achremowicz, B.; Piskuła, M.K.; Zieliński, H. Phenolic Compounds from Apples: Reviewing their Occurrence, Absorption, Bioavailability, Processing, and Antioxidant Activity-A Review. Pol. J. Food Nutr. Sci. 2020, 70, 321-336. [CrossRef]

9. Mureşan, E.A.; Muste, S.; Borşa, A.; Vlaic, R.A.; Mureşan, V. Evaluation of Physical-Chemical Indexes, Sugars, Pigments and Phenolic Compounds of Fruits from Three Apple Varieties at the End of Storage Period. Bull. UASVM Food Sci. Technol. 2014, 71, 45-50. [CrossRef]

10. Kschonsek, J.; Wolfram, T.; Stöckl, A.; Böhm, V. Polyphenolic Compounds Analysis of Old and New Apple Cultivars and Contribution of Polyphenolic Profile to the In Vitro Antioxidant Capacity. Antioxidants 2018, 7, 20. [CrossRef]

11. Francini, A.; Romeo, S.; Cifelli, M.; Gori, D.; Domenici, V.; Sebastiani, L. ${ }^{1}$ H NMR and PCA-based analysis revealed variety dependent changes in phenolic contents of apple fruit after drying. Food Chem. 2017, 221, 1206-1213. [CrossRef]

12. Duralija, B.; Putnik, P.; Brdar, D.; Bebek Markovinovíc, A.; Zavadlav, S.; Pateiro, M.; Domínguez, R.; Lorenzo, J.M.; Bursác Kovăcevíc, D. The Perspective of Croatian old apple cultivars in extensive farming for the production of functional foods. Foods 2021, 10, 708. [CrossRef]

13. Iacopini, P.; Camangi, F.; Stefani, A.; Sebastiani, L. Antiradical potential of ancient Italian apple varieties of Malus x domestica Borkh. in a peroxynitrite-induced oxidative process. J. Food Compos. Anal. 2010, 23, 518-524. [CrossRef]

14. Oszmiański, J.; Lachowicz, S.; Gamsjäger, H. Phytochemical analysis by liquid chromatography of ten old apple varieties grown in Austria and their antioxidative activity. Eur. Food Res. Technol. 2020, 246, 437-448. [CrossRef] 
15. Preti, R.; Tarola, A.M. Study of polyphenols, antioxidant capacity and minerals for the valorisation of ancient apple cultivars from Northeast Italy. Eur. Food Res. Technol. 2021, 247, 273-283. [CrossRef]

16. Wandjou, J.G.N.; Sut, S.; Giuliani, C.; Fico, G.; Papa, F.; Ferraro, S.; Caprioli, G.; Maggi, F.; Dall'Acqua, S. Characterization of nutrients, polyphenols and volatile components of the ancient apple cultivar 'Mela Rosa Dei Monti Sibillini' from Marche region, central Italy. Int. J. Food Sci. Nutr. 2019, 70, 796-812. [CrossRef]

17. Simonato, B.; Marangon, M.; Vincenzi, S.; Vegroban, M.; Pasini, G. Evaluation of the phenolic profile and immune reactivity of Mal d 3 allergen in ancient apple cultivars from Italy. J. Sci. Food Agric. 2020, 100, 4978-4986. [CrossRef] [PubMed]

18. Francini, A.; Galleschi, L.; Saviozzi, F.; Pinzino, C.; Izzo, R.; Sgherri, C.; Navari-Izzo, F. Enzymatic and non-enzymatic protective mechanisms in recalcitrant seeds of Araucaria bidwillii subjected to desiccation. Plant Physiol. Biochem. 2006, 44, 556-563. [CrossRef] [PubMed]

19. Bouayed, J.; Deußer, H.; Hoffmann, L.; Bohn, T. Bioaccessible and dialyzable polyphenols in selected apple varieties following in vitro digestion vs. their native patterns. Food Chem. 2012, 131, 1466-1472. [CrossRef]

20. Ullah, C.; Unsicker, S.B.; Fellenberg, C.; Constabel, C.P.; Schmidt, A.; Gershenzon, J.; Hammerbacher, A. Flavan-3-ols Are an Effective Chemical Defense against Rust Infection. Plant Physiol. 2017, 175, 1560-1578. [CrossRef]

21. Lu, Y.; Chen, Q.; Bu, Y.; Luo, R.; Hao, S.; Zhang, J.; Tian, J.; Yao, Y. Flavonoid accumulation plays an important role in the rust resistance of Malus plant leaves. Front. Plant Sci. 2017, 8, 1286. [CrossRef] [PubMed]

22. Zielinska, D.; Laparra-Llopis, J.M.; Zielinski, H.; Szawara-Nowak, D.; Giménez-Bastida, J.A. Role of apple phytochemicals, Phloretin and Phloridzin, in modulating processes related to intestinal inflammation. Nutrients 2019, 11, 1173. [CrossRef]

23. Shiv, K.; Sinha, K.; Sharma, R.; Purohit, R.; Padwad, Y. Phloretin and phloridzin improve insulin sensitivity and enhance glucose uptake by subverting PPAR $\gamma /$ Cdk5 interaction in differentiated adipocytes. Exp. Cell Res. 2019, 383, 111480.

24. Hrubá, M.; Baxant, J.; Čížková, H.; Smutná, V.; Kovařík, F.; Ševčík, R.; Hanušová, K.; Rajchl, A. Phloridzin as a marker for evaluation of fruit product's authenticity. Czech. J. Food Sci. 2021, 39, 49-57. [CrossRef]

25. Agnolet, S.; Ciesa, F.; Soini, E.; Cassar, A.; Matteazzi, A.; Guerra, W.; Robatscher, P.; Storti, A.; Baric, S.; Oberhuber, M.; et al Dietary elements and quality parameters of 34 old and eight commercial apple cultivars grown at the same site in South Tyrol, Italy. Erwerbs-Obstbau 2017, 59, 171-183. [CrossRef]

26. Macit, I.; Aydın, E.; Tas, A.; Gundogdu, M. Fruit quality properties of the local apple varieties of Anatolia. Sustainability 2021, 13, 6127. [CrossRef]

27. Horsley, R.; Gökbel, H.; Özcan, M.M.; Harmankaya, M.; Şimşek, S. Monitoring of element contents of three different apple (Malus Spp.) varieties in an apple tree. J. Food Nutr. Res. 2014, 2, 127-129.

28. Ozcan, M.M.; Harmankaya, M.; Gezgin, S. Mineral and heavy metal contents of the outer and inner tissues of commonly used fruits. Environ. Monit. Assess. 2012, 184, 313-320. [CrossRef]

29. Udensi, U.K.; Tchounwou, P.B. Potassium Homeostasis, Oxidative Stress, and Human Disease. Int. J. Clin. Exp. Physiol. 2017, 4 , 111-122.

30. Todea, D.A.; Cadar, O.; Simedru, D.; Roman, C.; Tanaselia, C.; Suatean, I.; Naghiu, A. Determination of major-to-trace minerals and polyphenols in different. Not. Bot. Horti Agrobot. Cluj-Napoca 2014, 42, 523-529. [CrossRef]

31. WHO. Guideline: Sodium Intake for Adults and Children; World Health Organization (WHO): Geneva, Switzerland, 2012.

32. Bassi, M.; Lubes, G.; Bianchi, F.; Agnolet, S.; Ciesa, F.; Brunner, K.; Guerra, W.; Robatscher, P.; Oberhuber, M. Ascorbic acid content in apple pulp, peel, and monovarietal cloudy juices of 64 different cultivars. Int. J. Food Prop. 2017, 20, 2626-2634. [CrossRef] 